\title{
sciendo
}

\section{CONSIDERATIONS ON THE LEGAL PROTECTION OF THE ATMOSPHERE}

\section{Gheorghe Durac ${ }^{1}$}

Keywords: air quality, atmospheric pollution, greenhouse gases, environmental legislation, global warming, climate changes

\begin{abstract}
Air quality is an issue of general, global interest, which requires the implementation of appropriate environmental policies, taking into account the essential connection between the world economy and the environment. Air is an important natural element of the environment, vital for human life and health, as well as for fauna and flora, and it needs to be protected by all means, including legal methods.

Lately, scientific studies and researches have shown that the chemical structure of the atmosphere is changing for natural or anthropogenic causes, which requires more effective monitoring of the impact of human activity on the atmosphere, doubled by the implementation of radical measures, including legal ones, meant to insure the protection of this environmental element.

The increase in the quantity of polluting gases eliminated into the atmosphere causes global warming, destroying the ozone layer and generating other imbalances in the natural environment.

In these conditions, and since pollution knows no political-administrative borders, being a global phenomenon, there is an absolute need for international cooperation based on conventions and treatises on this topic, or directives from international bodies and organisations, and at a national level, the environmental legislation must aim to protect the air in the troposphere as well as the other elements outside the troposphere, such as the ozone layer, which is part of the stratosphere.
\end{abstract}

\section{Preliminaries}

In order to preserve life on Earth, air and water are the elements with the highest contribution - in their absence, it is impossible to imagine the existence of the living world in the form we currently know. Knowing that oxidation is the main source oif energy for vital processes, we can say that out of the constituents of air, oxygen is essential for animal and vegetal breathing. Vegetation insures and receives oxygen reserves from the atmosphere, a reserve that is not enough for

${ }^{1}$ PhD Professor, “A1.I.Cuza” University, Iasi, gheorghe.durac@uaic.ro 
consumption. However, ocean water, with the help of phytoplankton, also generates an important quantity of oxygen (above 70\%) which is absorbed into the atmosphere, thus insuring a natural balance between oceans and air.

Unfortunately, man's activities have uncontrolled effects, which have caused the imbalance, even the destruction of the equilibrium between oxygen production and consumption. Recent scientific research have stressed the fact that the chemical structure of the atmosphere is changing not only because of natural causes but also because of anthropogenic effects. Lately, it has become more and more obvious that various human activities have attacked the atmosphere through a significant increase in the resulting polluting gases, which has also been contributing to global warming, to the destruction of the ozone layer, and to other imbalances of natural factors (Durac, 2019).

Oxygen circulation cannot be separated from carbon dioxide, the latter being absorbed by vegetation and decomposed into carbon (which is then assimilated for growth) and oxygen, which is restored into the atmosphere. The continuous repetition of this cycle represents and insures a vital balance in the atmosphere.

Without a doubt, we cannot say that in nature and naturally, the balance we have been mentioning is perfect. Even without the harmful intervention of man, the atmosphere is not pure, since a series of natural phenomena, such as the decomposition of animal and vegetal matter, volcanic eruptions, forest fires, and other such events trigger solid and gas particles to penetrate the atmosphere, but such phenomena cannot disrupt the natural equilibria in such a way as to endanger the existence of life in Earth, since nature has its own ability to regulate itself.

\section{Air pollution and its consequences}

Air protection must be achieved by all means, including legal, considering that this natural environmental element is vital for the life and health of man, flora, and fauna (Bostan I., Iatco C., Hlaciuc E., Epure T., 2009). At the same time, air as a transit path for pollutants, allows the easy and fast distribution of polluting elements, which can rapidly affect vast areas, spread over remote distances from the source of pollution.

As such, the pollution of this natural environmental factor cannot be stopped at the borders of one state or region. For this particular reason, this phenomenon is a serious problem that appears globally and can only be controlled with the combined effort of all states, through international cooperation leading to the adoption of concrete measures meant to insure the monitoring of pollution sources and preventing harmful emissions into the atmosphere, with such unfortunate consequences.

Air is a mixture of gases, present in the lower layers of Terra's atmosphere. Law no. 104/2011 on surrounding air quality defines the atmosphere as the layer of 
air around Earth, respectively the air mass surrounding the Earth's surface, including the ozone layer.

In its pure form, air is composed of oxygen, nitrogen, and carbon dioxide. However, natural air also contains other compounds, more or less polluting, in gas, liquid, or solid form (Duțu, 2007).

Mainly caused by human activities with a high risk of pollution, but also by the peculiarities if the atmosphere, air pollution consists either of the modification of the proportions of the various components, or of the penetration into the atmosphere of foreign bodies, such as organic synthesis substances or radioactive elements.

Air pollution is a very serious problem, with negative consequences not only for the natural environment, but also from an economic and social perspective, which has also required adopting urgent and firm measures, including legally, in order to limit pollution (Bostan I., Condrea P., Burciu A., 2009).

The first legislative step in this direction implies defining the notion of air pollution. Thus, according to a series of documents adopted by the European Council, such as the European Council Resolution concerning the fight against air pollution of March 8, 1968 or the European Council Report for Environmental Protection of September 1997, state that air pollution is determined by the presence of foreign substances or by the variations of air components, causing damaging effects, which duet o the peculiarities of this environmental factor, propagate on a large scale - regional or even global.

Air quality is affected by the quantity of pollutants issued into the atmosphere, and the negative consequences can also be enhanced by meteorological such conditions as the circulation or air masses or rainfall. Locally, the main causes of pollution are the emissions of industrial units and the air and road traffic. Globally, pollution is represented by pollution present in all local areas, plus a series of phenomena that occur on a large scale: acid rain, the destruction of the ozone layer, the greenhouse effect, and many others, all of which determine global warming and cause visible climatic change (Duţu, 2007).

The pollutants that contaminate the atmosphere are numerous and greatly diverse. The activities that produce the highest atmospheric pollution are industry, transport, and household heating using fossil fuel (gas, coal, oil). The multiple pollution sources are varied. There are natural as well as anthropic causes; fixed and mobile sources; surface and volume sources; continuous, intermittent, and instantaneous sources (Lupan, 2009).

The negative consequences of air pollution are multiple and they affect human, plant, and animal health and life, causing at the same time phenomena such as malnutrition, underproduction, etc., and affecting both the natural and the artificial environment. 
According to their source, air pollutants may be primary pollutants (which are issued directly from known sources) or secondary pollutants (generated by the interaction of harmful substances between each other, or with certain air components). The main pollutants of the atmosphere are: sulphuric, carbonic, mineral pollutants, compounds of nitrogen, powders in the form of ashes and smoke, bacterial dust, radioactive substances, sound pollutants, etc. (Marinescu, 2010). It has been estimated that annually, hundreds and thousands of millions of tons of such pollutants are absorbed into the atmosphere. If, for example, in 1850, the concentration of $\mathrm{CO} 2$ in the atmosphere was $280 \mathrm{~cm} 3 / \mathrm{m} 3$ air, at present this concentration exceeds $350 \mathrm{~cm} 3 / \mathrm{m} 3$ air.

The main visible effects of this type of pollution are, first of all, climate changes, enhanced and generated by the so-called greenhouse effect, which, because of the gas emissions, determine an alarming raise in the average temperature all over the globe.

Second, as another effect of air pollution, we can notice the degradation of the ozone layer as a result of the increase in the concentration of chlorides, bromines, substances used in the refrigerating industry, in ventilation, etc. The ozone layer is 10-14 km away from the surface of the earth and plays a role in retaining ultraviolet radiations, containing up to $90 \%$ of atmospheric ozone. Measurements have revealed that between 1979-1991, the thickness of the ozone layer was reduced by $3 \%$, which is alarming for the future of humankind.

Acidification (acid plaque) is another negative consequence of air pollution, which is caused by the combustion processes that causes the emission into the atmosphere of sulphur and nitrogen oxides, which seriously affect the ecosystems with which they interfere.

Finally, another effect of atmospheric pollution is smog, a result of photochemical reactions that dissociate sulphur dioxide, thus forming nitrogen monoxide and atomic oxygen, products that can initiate and sustain chain reactions with free radicals. The most important secondary pollutant that results from the involvement of hydrocarbon to this cycle is ozone, which is toxic at the ground level.

\section{Legal protection of the atmosphere within the European Union}

Considering that, as already mentioned, air pollution does not stop at state borders, but it affects large areas, which may exceed even continental limits, it is necessary to refer here to the notion of cross-border atmospheric pollution, which was defined during the Geneva Convention on Transboundary Air Pollution in 1979 as ,the introduction by man, directly or indirectly, of substances or energy into the air resulting in deleterious effects of such a nature as to endanger human 
health, harm living resources and ecosystems and material property and impair or interfere with amenities and other legitimate uses of the environment."

The definition of this form of pollution is based on the notion of long-range transboundary pollution, which was regulated by the Convention on Long-Range Transboundary Air Pollution (signed by Romania via Law no. 8/1991, published in Monitorul Oficial no. 18 of January 26, 1991), and it refers to pollution whose physical source is included (in total or in part) in the national jurisdiction area of a certain state, and which can cause damaging effects in an area subject to the national jurisdiction of another state, over a distance on which it is not generally possible to distinguish the contribution of polluting sources (Lupan, 2000).

Although over the last decades, air quality has improved in Europe to a good extent, air pollution is still the main cause of the negative consequences felt in the European natural environment. Although within the European Union, the standards on air quality are extremely high, meeting them is often difficult, as issues arise in applying the strategies and measures meant to reduce global warming and climate change.

The European Union has actively participated in all international meetings on environmental topics and has contributed to adopting conventions and protocols that establish a series of measures and commitments, subsequently translated into compulsory directives for the member states.

Obviously concerned with the issues of air quality ever since the 70's, the European Community has instated a monitoring and control system on atmospheric emissions, especially in the case of transport and energy production activities. In this respect, it has adopted a legislation that aimed to reduce the concentrations of carbon monoxide, lead, sulphur dioxide, benzene, and nitrogenised oxides.

Concretely, in order to improve air quality, the principles and objectives of the strategy for air, water, and soil quality have been laid down (Directive no. 96/62/EC), and the global strategy "Clean Air for Europe (CAFE)" was adopted in 2000 and launched one year later, including a series of objectives, of which we mention: the development, collection, and validation of scientific information on the effects of atmospheric pollution; the implementation, effectiveness analysis, and enriching of existing legislation; dissemination of the information to the public.

The European Union, an active participant in the World Summit for sustainable development held in Johannesburg in 2002, has subsequently applied the commitments taken, in the same way as it did following the results of the Aarhus Convention (in 1998) concerning access to information, the public's involvement in decision-making and access to justice in environmental issues.

Also, although the Kyoto Protocol had been signed as early as 1998, Decision 2002/358/EC approves this protocol in the name of the European Community, with the Member States taking a vow to apply their instruments in order to sign it at the 
same time as the European Union, before the start of the World Summit of Johannesburg. Later, within the European Council organised in Brussels in March 2003, concrete measures were set referring to the emission reduction scheme for gases that cause greenhouse effects, and decisions were adopted concerning environmental liability.

In order to reduce the concentrations of harmful substances, several directives and regulations have been adopted: Directive no. 1999/30/EC (reduction of the concentrations of sulphur dioxide, nitrogenised oxides, and lead); Directive no. 85/203/EEC (nitrogen dioxide); Regulation no. 2037/2000/EC (reduction of the substances that damage the ozone layer); Directives no. 82/884/EEC and no. 2001/81/EC (which set maximum allowed limits for certain atmospheric pollutants).

Through the adopted legislation, the European Union has permanently aimed to reduce the emissions caused by industrial activities and transport.

In the view of reducing air pollution caused by industrial activities, the European Union adopted: Directive no. 2001/80/EC that limits the emissions into the atmosphere of certain pollutants coming from large combustion installations; Directive no. 94/63/EC of the European Parliament and Council of December 20, 1994 concerning the control of volatile organic compounds (VOC) resulting from depositing fuels and their distribution from the terminals to the fuel distribution units; Directive no. 96/61/EC concerning pollution prevention and integrated control.

The European Union has urged the industrialised states to take concrete and efficient actions to reduce and limit the emissions of gases that cause a greenhouse effect. To this purpose, Decision 280/2004/EC of the European Parliament and Council introduced a mechanism meant to monitor anthropic emissions of greenhouse gases and to evaluate the progress made in complying with the commitments taken with regards to these emissions. The application of this mechanism, initially introduced in 1993 by another directive, has led to a drop by $2.4 \%$ of the emissions of greenhouse gases in 2001, compared to the value recorded for 1990.

In the field of transport, the profile strategy aims for three main objectives: reducing polluting emissions (Directives no. 70/220/EEC, 88/77/EEC, 93/12/EEC and 98/70/EC), reducing fuel consumption for vehicles owned by natural persons (Directive no. 1999/94/EC and Decision no. 1753/2000/EC), and promoting nonpolluting vehicles. In order to reduce air pollution caused by the vehicles used in agriculture and forestry, Directive no. 2000/25/EC establishes the standards of acceptable emissions for these vehicles.

In 2000, a debate was launched on the measures to reduce the gases with a greenhouse effect, under the Green Book titled "Towards a European Programme 
concerning Climate Change" - COM (2000) 87, which initiated the European Climate Change Programme (ECCP), aiming to implement a community policy concerning the negotiation of greenhouse gases before the application of the Kyoto Protocol.

\section{Legal Protection of the Atmosphere in Romania}

In our country, the legal framework concerning air protection has as a starting point Law no. 104/2011 concerning the quality of environmental air, a normative act that translates Directive 2008/50/EC of the European Parliament and Council on the quality of environmental air and cleaner air for Europe, as well as Directive 2004/107/EC of the European Parliament and Council concerning arsenic, cadmium, mercury, nickel, and polycyclic aromatic hydrocarbons in the air. This framework normative act develops the dispositions of art. 136 paragraph 3 of Romania's Constitution, which states that the air space, together with the other public riches, is the exclusive object of public property and is subject to a legal regime of higher protection.

Also, the Environmental Protection Law (no. 265/2006, which approves the Emergency Order no. 195/2005) dedicates an entire chapter to air protection, climate change, and the management of environmental noise, establishing for the dedicated public central authorities a series of attributions, among which drafting, promoting, and updating the National Strategy in the field of air protection and the National Action Plan in the field of Atmospheric Protection. At the same time, the law requires the same authorities to draft, promote, and, as the case may be, to update the National Programme for the reduction of sulphur dioxide, nitrogen oxides, and dusts resulted from large combustion installations, as well as to organise the air quality monitoring activity for the entire country, setting more restrictive limit values through the regulating acts, in order to comply with national emission ceilings, and respectively with surcharges and critical levels.

We must stress the fact in the field of air protection, the law gives numerous attributions to a vast array of public authorities, of which we mention: the Ministry of Environment; the Air Quality Evaluation Centre (CECA); the National Reference Laboratory for Air Quality (LNRCA); the National Meteorology and Climatology Body; the Central Public Authority for Forestry; the Central Public Authority for Urban Planning and Public Works; the Central Public Authority for Industry and Transport; the Central Public Authority and territorial public authorities for inspection and control in the field of environmental protection (Oneț, 2017).

Air quality in Romania is permanently monitored through over 140 automated stations distributed all over the country, which are part of the National Air Quality Monitoring Network (RNMCA). These stations are provided with automatic 
scanners that continuously measure the concentration of pollutants in the air: sulphur dioxide, nitrogen oxides, carbon monoxide, benzene, ozone, suspension particles in aerosols. In addition, laboratory equipment is used to measure the concentration of heavy metals: lead, cadmium, arsenic, nickel, the concentration of suspension particles in aerosols and deposits. The monitoring stations are placed in accordance with the criteria established by the European directives on air quality, in order to protect human health, the vegetation and ecosystems, in the view of evaluating the various types of polluting emissions. There are four categories of air quality monitoring stations: traffic stations (that evaluate the influence of traffic on air quality); industrial stations (that evaluate the influence of industrial activities on air quality); urban and suburban background stations (that evaluate the influence of urban settlements on air quality); rural and regional background stations (that evaluate air quality in areas that are far away from emission sources).

In order to translate the provisions of Directive no. 94/63/EC regarding the emission control of volatile organic compounds resulted from gas storage and distribution from terminal stations to service stations, the following normative acts were adopted: Law no. 264/2017 that establishes the technical requirements for limiting volatile organic compounds emissions (VOC), resulting from gas storage and distribution from terminals to gas distribution stations, as well as during car fuelling in gas stations; Ministry Order no. 781/2004 for the approval of the Methodological Norms concerning measuring the emissions of volatile organic compounds resulting from gas storage and loading/unloading at terminals; Ministry Order no. 337/2001 for the approval of the Norms concerning the technical inspection of the installations, equipment, and devices used in order to limit the emissions of volatile organic compounds resulting from gas storage, loading, unloading, and distribution to terminals and gas stations.

In compliance with the policies and strategies established within the European Union, our country drafted the National Strategy for Atmospheric Protection, approved by Decision no. 586/2004, which was structured and updated in several stages. The main objectives laid down by this strategy refer to: the integrated evaluation and management of air quality; the implementation of the requirements for pollution prevention and integrated control; the implementation of the requirements to limit the emissions of air pollutants coming from large combustion installations; the implementation of the requirements to eliminate substances that destroy the ozone layer; meeting the national provisions in the field of climate change, etc.

The National Strategy for Atmospheric Protection also includes the National Action Plan for Atmospheric Protection, which establishes the methods and means for complying with the objectives mentioned in the Strategy, of which we mention: preserving air quality in areas that meet the limits foreseen by the applicable norms 
for quality indicators; improving air quality in the areas that do not meet the limits foreseen by the applicable norms for quality indicators; adopting the necessary measures to limit and, if possible, eliminate the negative effects on the environment, in a transboundary context; fulfilling the obligations taken with the international agreements and treatises that Romania is part of, and participating in international cooperation in the field.

According to the applicable legislation, evaluating the quality of surrounding air is compulsory for all agglomerations and areas on Romania's territory. The evaluation method is established according to the level of the relevant pollutants in the air. Air quality evaluation is performed through methods and procedures established through Government decisions, and the air quality evaluation results are made known to the public and reported to the European Commission by the central public authority for environmental protection. The reference pollutants that are monitored in the view of the air quality evaluation, the threshold values, the alert levels, the target values, and the tolerance margins in relation to the air pollution level, as well as the selection criteria for these pollutants, are all established in agreement with the community standards, through Government decisions. Based on the data obtained via the air quality evaluation, the competent environmental authority drafts and promotes action plans for air quality.

The Air Quality Evaluation and Integrated Management National System, approved by the Government decision no. 586/2004, aims to insure the organisational, institutional, and legal framework for the cooperation of public authorities and institutions that are competent in the field of atmospheric protection and air quality evaluation and management on Romania's territory. This includes two integrated parts: the National air quality monitoring system and the National atmospheric pollutants emissions inventory system. The information provided by the two sub-systems are corroborated by the Air Quality Evaluation Centre in compliance with the national and international standards in the field of air quality evaluation and management. The National Air Quality Monitoring Network includes 41 local centres, which collect and transmit the data provided by the stations to public information panels, and following the primary validation, they send this data for certification to the National Reference Laboratory in Bucharest.

\section{Conclusions}

Although consistent efforts are made to improve air quality, on the political, economic, as well as on the legal level, air pollution continues to trigger significant climate changes, as well as multiple health issues for the population. Coal is still an energy source with high level of carbon emissions, representing approximately $20 \%$ of the total emissions of greenhouse gases. A gradual decrease in the usage of 
coal in producing electrical and thermal energy in Europe would be a compulsory first condition in order to prevent the long-term effects on health that are cause by climate changes, and at the same time improving people's health.

The objectives followed by the European Union in the field of air protection can only be achieved to the extent to which all the political and decision-making factors will adopt a responsible and united attitude for the pollution thresholds foreseen to be reduced from the start of the millennium to be reached by 2020 , through actions taken together by the Member States and by the European Union in collaboration with other international bodies. A substantial reduction of the negative effects that pollution generates on the people's health and on the environment as a whole will facilitate reaching a consensus between the European Union standards concerning environmental air quality and the reference objectives set forth by the World Health Organisation.

A solid, coherent, and sustained policy in the field of air quality will meet the citizens' aspirations with regards to their health and well-being, generating at the same time direct economic benefits. Improving productivity and reducing medical assistance costs fully compensates the compliance costs, and this policy is foreseen to result in a net growth of the degree of occupation of the workforce. At the same time, on the world technology and service markets there will appear a series of opportunities meant to reduce emissions, which are already rapidly expanding. As such, the European Union can gain a competitive advantage and capitalise upon these opportunities by focusing its research and development activities on technologies that are more efficient from the perspective of the use of resources and less polluting, which other countries would also be interested in adopting sooner or later.

\section{Bibliography}

Bostan I., Iatco C., Hlaciuc E., Epure T. (2009), Responsibility and Accountability in the Preservation of Natural Life Conditions, în „Revue Romanian Journal of Bioethics”, Volume 7, nr. 2.

Bostan I., Condrea P., Burciu A. (2009), Involvment of legal responsability severe acts of pollution and noncompliance, în "Environmental Engineering And Management Journal, Volume 8, No. 3.

Durac G. (2019), The Legal Protection of Environmental Factors - A Premise for Sustainable Development, to the International Business Information Management Conference (33th IBIMA), 10-11 april 2019, Granada, Spania.

Duțu M. (2007), Tratat de dreptul mediului, $3^{\text {rd }}$ edition, C.H. Beck Publishing House, Bucharest, p. 659. 
Lupan E. (2009), Tratat de dreptul mediului, C.H. Beck Publishing House, Bucharest, p. 284-286.

Lupan E. (2000), Dicţionar de protecţia mediului, Cluj - Napoca, p.164.

Marinescu D. (2010), Tratat de Dreptul mediului, $4^{\text {th }}$ edition revised and enlarged, Universul Juridic Publishing House, Bucharest, p.116.

Oneț C. (2017), Dreptul mediului, Editura Universul Juridic, Bucharest, p. 266-278.

*** Law no. 104/2011 concerning surrounding air quality, published in Monitorul Oficial no. 452 of June 28,2011

*** Governmental decision no. 586/2004 concerning the establishment and organisation of the National Air Quality Evaluation and Integrated Management System, published in Monitorul Oficial no. 389 of May 3, 2004.

*** Council Directive no. 96/62/EC, of September 27, 1996, concerning the evaluation and management of environmental air.

*** Directive 2008/50/EC of the European Parliament and Council, of May 21, 2008, concerning the environmental air quality and cleaner air for Europe.

*** EU 2015/2193 of the European Parliament and Council, of November 25, 2015, limiting the emissions into the atmosphere of certain pollutants resulting from medium combustion installations.

*** Decision 280/2004/EC of the European Parliament and Council, of February 11, 2004 regarding a greenhouse gases monitoring mechanism within the EC. 